\title{
La libertad conquistada: \\ Consideraciones sobre manumisión, gratitud y coerción en Charcas colonial (siglos XVI-XVIII)
}

\author{
The Freedom conquered: \\ Considerations on manumission, gratitude and coercion in \\ colonial Charcas (XVIth-XVIIIth Centuries)
}

\author{
Paola A. Revilla Orías \\ Universidad Católica Boliviana "San Pablo"; \\ Universidad Mayor de San Andrés (Bolivia) \\ Bonn Center for Dependency and Slavery Studies (Alemania) \\ p.revillao@gmail.com
}

\begin{abstract}
Resumen
El texto se adentra en las formas de manumisión de esclavos que residieron en la ciudad de La Plata, Charcas colonial. Propone su análisis como procesos complejos, develando mecanismos coercitivos desplegados por los amos para perpetuar el control sobre los esclavizados, así como la hábil acción de estos en su lucha por la consecución de la libertad legal. Estudia los efectos de la violencia de la palabra no cumplida, no escrita y no respetada, que arriesgó con sumergir a los coartados, libertos, manumisos en un limbo de servidumbre no-libre por tiempo indefinido. Así también, de la gratitud como valor social de corte paternalista que legitimó relaciones asimétricas de dependencia y pudo condicionar a las personas a vivir en servidumbre.
\end{abstract}

Palabras Clave

Esclavitud; manumisión; Charcas, libertos; no-libre; coerción laboral.

\begin{abstract}
The study focuses on the forms of manumission of enslaved who resided in the city of La Plata, Charcas. It proposes their analysis as complex processes, and reveals coercive mechanisms deployed by the masters to perpetuate control over the enslaved, as well as the skillful action of these in their fight for the achievement of legal freedom. It analyzes the effects of the violence of the unfulfilled, unwritten and not respected word, which risked submerging the coartados, freedmen, manumisos in a limbo of indefinite unfree servitude. Likewise, of gratitude as a social value of a paternalistic nature that legitimized asymmetric dependency relationships and could condition people to live in servitude. From these cleavages, appealing to a qualitative methodological strategy based on the survey of bibliography and written sources, we seek to carry out both a comparative analysis of the aforementioned organizations, and a balance of academic production on them, highlighting outstanding contributions and challenges for a research agenda on the subject.

Esta obra está sujeta a la Licencia Reconocimiento-NoComercial-CompartirIgual 4.0 Internacional de Creative Commons. http://creativecommons.org/licenses/by-nc-sa/4.0/

(cc) EY-NC-SA
\end{abstract}




\section{Paola A. Revilla Orías}

\section{Keywords}

Slavery; manumission; Charcas; freedmen; unfree; labor coercion.

\section{Introducción}

El paso de la esclavitud a la libertad legal no fue un proceso lineal ni sus códigos sencillos de descifrar y utilizar para la población africana y afrodescendiente en las colonias sudamericanas. La manumisión no puede ser concebida dentro de una unidad de sentido. En algunos casos ha sido presentada de forma esquemática en los distintos tipos que conoció, según describía la normativa. Pero claro, no hubo un solo corpus jurídico para regular la esclavitud en América. Las Siete Partidas de Alfonso $X$ por ejemplo, fue más un conjunto de recomendaciones que de leyes propiamente dichas, poco adaptadas a los escenarios coloniales. Es así que los jueces locales, con autorización real, acudieron con frecuencia a la casuística para dirimir dentro de los contextos diversos de esclavización en los que tomaron sus determinaciones. Además de la norma escrita, el análisis debe mirar las prácticas manumisorias y considerar las sutiles diferencias y conexiones que pudo haber entre las formas que conocieron en cada lugar.

Este busca contribuir a la lectura histórica de un fenómeno complejo que condicionó y muchas veces determinó la vida de esclavos, libertos y de su descendencia. Conecta con la reflexión que se viene encaminando sobre el tema en distintas regiones y propongo el acercamiento a un contexto poco conocido, el de la jurisdicción de La Plata sede de la Real Audiencia de Charcas (Bolivia) colonial. A través de la revisión y análisis de datos inéditos salidos de diversos expedientes judiciales y escrituras notariales, se cuestiona sobre las voluntades imperantes para manumitir y buscar la manumisión en este escenario. Reflexiona sobre la violencia de ciertos mecanismos coercitivos que fueron puestos en marcha por los amos y sus parientes para intentar frenar las concesiones de libertad, y sobre lo que pudo significar para los manumisos la adquisición de una nueva condición legal. Más importante aún, cuestiona la afirmación según la cual en Charcas los esclavos difícilmente podían acceder a la libertad si no era por gracia de sus amos, dejando ver el sesgo metodológico que yace en esta interpretación.

\section{La libertad como posibilidad}

La mirada a la libertad personal varía según el lugar, el tiempo y la sociedad que piensa el concepto. Así también, la proyección jurídica del término no siempre coincide con la experiencia humana. En Sudamérica de los siglos XVI-XIX, y más concretamente en la jurisdicción de la Real Audiencia de Charcas en la que me concentro en este estudio, la población internalizó en la convivencia la idea de que 


\section{La libertad conquistada: Consideraciones sobre manumisión, gratitud y coerción en Charcas colonial (siglos XVI-XVIII)}

las personas eran de dos tipos según su condición normada: libres y esclavos. ${ }^{1}$ La institución esclavista vigente en la España del siglo XVI fue rápidamente asimilada e integrada en léxico y prácticas en Charcas. Legitimada por la patrística católica y validada por la monarquía española, la lectura aristotélica de la sociedad que validaba la predestinación natural de algunas personas a la esclavitud fue moldeando las relaciones interpersonales coloniales. ${ }^{2}$

Desde muy pronto después de la fundación de la villa de (La) Plata (1538), sede de la Audiencia, gran parte de la población participaba del sistema esclavista en la urbe y chacras de los alrededores. Pedro Ramírez del Águila (1639: 74) refiere que en las primeras décadas del siglo XVII estuvo habitada por alrededor de 14.000 personas, un universo variado en cuanto a procedencia, culturas y credos. La institución esclavista de impronta europea fue combinada con ciertas claves de sistemas laborales prehispánicos en un contexto particular e inédito de dominación, el colonial (Tandeter, [1976] 2015).

No existen estudios demográficos que nos permitan decir con precisión cuántos africanos y sus descendientes esclavizados residieron en La Plata en los siglos XVI y XVII. Los informantes suelen hacer estimaciones generales y subjetivas. No se trataba en todo caso de una sociedad esclavista de grandes dimensiones como pudieron ser aquellas de plantación, pero según advirtió Alberto Crespo (1995), el ingreso de esclavizados fue constante a lo largo de todo el periodo colonial, legalmente y por contrabando (Sempat,1965; Hanke, 1956; Studer,1958; Crespi, 2000; Rosal, 2011).

Dicho esto, la esclavitud debe entenderse en la pluralidad de sus expresiones ya que no involucró jurídicamente solo a los africanos y a sus descendientes nacidos en Charcas, sino también a indígenas de las tierras bajas del surandino hechos cautivos para trabajar en las urbes y chacras coloniales ${ }^{3}$. Sin desmerecer la violencia de los mecanismos de esclavización legal de personas de origen africano, se puede constatar que el espectro de población involucrada en este sistema fue mucho más amplio. Fray Miguel Agia (1604: 80) refiere en 1604: "hacen mal los chacareros y otros cualesquiera hombres del distrito de la Real Audiencia de Chuquisaca, que compran indios ... lo hacen peor los que contra toda razón y justicia tienen los indios en perpetua esclavonía y servidumbre desde que nacen hasta que mueren". La constatación de su esclavización incluso después de legalmente prohibida la práctica, lleva a tomar consciencia de la pertinencia de una perspectiva menos

\footnotetext{
${ }^{1}$ La Real Audiencia de Charcas (1559) comprendió el Collasuyu, Cuzco (desmembrado en 1573), Tucumán, Juries y Diaguitas, Chunchos-Moxos y los territorios colonizados por Andrés Manso y Nuflo de Chávez (Barnadas 1973: 513). La Plata, su sede, se encontraba a $80 \mathrm{~km}$ de Potosí, y era una plataforma estratégica para el control político-administrativo de la zona. Los españoles habían llegado al territorio cerca de ocho décadas después que los incas.

${ }^{2}$ Juristas y teólogos como Antonio de Herrera, Juan de Solórzano y Pereira, Luis de Molina y Diego de Avendaño la justificaron como un mal necesario para el sostenimiento de las Indias.

${ }^{3}$ Grupos guaraní-hablantes homogeneizados bajo el denominativo: "chiriguanos", residentes en de las actuales Santa Cruz, Chuquisaca y Tarija en Bolivia, y en el noroeste argentino. Su irreductibilidad al modelo español provocó que fuesen tenidos como traidores a la Corona y bárbaros infieles a la fe católica. Saignes, 2007; Combès \& Saignes, 1991.
} 


\section{Paola A. Revilla Orías}

esencializadora y etnificadora en la mirada a la esclavitud en perspectiva histórica (Boccara, 2018; Revilla, 2021).

Cabe destacar además que, según muestra la documentación, los indígenas esclavizados de tierras bajas no recibían el mismo trato y ciertos cuidados que los señores/amos solían tener con los esclavizados africanos debido a que su costo como piezas era menor, y les significaban menos pérdida. Por otro lado, aunque comerciados y esclavizados ilegalmente en el siglo XVII, los señores para quienes trabajaban solían ampararse en su condición de vasallos libres del rey cuando le convenía, usualmente para evitar algunas obligaciones que debía a su servidumbre esclava, como las curaciones y la vestimenta. Eso sí, el sentimiento de propiedad que expresaron con su servidumbre fue mucho más allá de la condición legal que los trabajadores tenían.

Ahora bien, una particularidad de la condición de esclavo durante la monarquía católica española, diferente de aquella de los esclavos de las colonias británicas, holandesas y francesas, es que podían adquirir su libertad legal de diferentes formas. La llamada manumisión fue práctica regular en toda Charcas con los esclavos de origen africano y afrodescendiente, no así con los indígenas chiriguanos. Esto se debe posiblemente a que el periodo de su esclavización legal fue corto. Prohibida la práctica, su esclavización ilegal no daba opción a la adquisición de la libertad legal, de la que se suponía gozaban como trabajadores y como súbditos del rey. Eso sí, los abusos cometidos contra sus personas movieron intensas demandas judiciales como las que llevaran adelante los afrodescendientes esclavizados que, viendo sus derechos vulnerados, tuvieron ocasión de acudir a los tribunales. ${ }^{4}$

Dicho esto, sabemos que no solo hubo distintas formas de manumisión sino que la Corona aceptó en América la codificación de otras varias además de las practicadas en España (Klein \& Vinson, 2008). Una serie de circunstancias favorables debía mediar para que un esclavo pudiese acceder a ellas y, buena parte, nunca pudo. El tipo de relación con el amo o ama, las redes familiares y de amigos que el esclavo iba tejiendo y la actividad u oficio al que se dedicaba eran fuertes condicionantes; así como el mayor o menor grado de autonomía financiera ganada en su desenvolvimiento en sociedad y el conocimiento de sus derechos y posibilidades legales.

\section{Sobre el gracioso perdón}

En Charcas como en otras regiones sudamericanas hay constancia de la adquisición de la libertad legal mediante la concesión o merced del amo, la manumisión graciosa, también conocida como "gracioso perdón" (Cortés Alonso, 1990; Rosal, 2011). Los factores que podían intervenir para que un amo decida liberar a su esclavo fueron como se podrá pensar, muy variables. Para entender un poco mejor esta realidad me

\footnotetext{
${ }^{4}$ Sobre demandas iniciadas por chiriguanos ante los tribunales de Charcas véase: Revilla, 2011.
} 


\section{La libertad conquistada: Consideraciones sobre manumisión, gratitud y coerción en Charcas colonial (siglos XVI-XVIII)}

he aproximado a las escrituras notariales de la ciudad de La Plata entre 1560 y 1630. Encontramos 63 actas notariales que conciernen diferentes procesos de manumisión. De estas, 59 son "cartas de libertad" entregadas por los amos a sus esclavos. Hay que notar que los esclavos y no siempre los amos, las hicieron transcribir ante notario para tener una constancia. Los otorgantes son en su mayoría hombres y, de las diez mujeres que figuran, varias son viudas.

Se podría pensar que los amos solían manumitir a sus esclavos cuando eran adultos mayores y no querían ocuparse de su vejez, la que les reportaba más gastos que beneficios, a ellos y a sus herederos. La realidad de La Plata, en sintonía con los hallazgos recientes para otras regiones, muestra que no siempre fue así. Los beneficiarios de la manumisión graciosa de este periodo, apenas más hombres que mujeres, tienen diferentes edades, sin que ningún rango etáreo sea predominante. Claro, estos datos no dan cuenta del abandono informal, situación que podía ser denunciada ya que era obligación del amo dar protección a su esclavo. Una sola acta de 1607 refiere que el amo, Juan de Cárdenas, daba libertad a Agustín Montenegro, su esclavo: "porque está viejo y ya ha servido". 5 Esto no quiere decir necesariamente que haya mediado la intención de desligarse de responsabilidades con Agustín; sino quizás de beneficiarlo con la nueva condición. ${ }^{6}$

Un aspecto importante a considerar es que el adjetivo "viejo(a)" e incluso la mención de cierta edad, nos da una imagen somera sobre su situación personal y como trabajadores. Los esclavos estuvieron enfrentados a condiciones laborales que provocaban el desgaste físico anticipado. Sin embargo, no podemos asumir mecánicamente las afirmaciones de quienes reflexionan sobre contextos laborales como los de las grandes haciendas, donde la esperanza promedio de vida de un esclavo era de 45 años, para escenarios como el charqueño en el que estuvieron mayormente dedicados a la agricultura a pequeña escala en estancias y huertas, así como al trabajo doméstico y estipendiario en las calles de la ciudad. La noticia de que en 1612 las esclavas Ana y Catalina fueron manumitidas en La Plata por decisión de sus amos, Alonso Vásquez y Mechor de los Reyes con 55 y 60 años de edad respectivamente, no implica que la principal razón de la concesión graciosa haya sido deshacerse de ellas en la vejez. ${ }^{7}$ Se debe uno preguntar también si hay más datos sobre el estado físico y anímico de los esclavizados, las tareas a la que los asignaron sus propietarios, si se desempeñaban en otras actividades, su grado de autonomía, sus redes familiares y sociales para saber si efectivamente quedaban desposeídas y marginadas al ser manumitidas. La libertad graciosa pudo ser en ocasiones muy bien ser recibida en edad avanzada.

\footnotetext{
${ }^{5}$ Archivo y Biblioteca Nacionales de Bolivia (ABNB): Escrituras Públicas (EP), Gaspar Núñez, 18. 09. 1607, f. 551.

${ }^{6}$ Dicho esto creemos prudente recordar la recomendación de Stuart B. Schwartz (1974: 619) de matizar esta lectura considerando que las manumisiones condicionales pudieron estar previstas para cuando el esclavo estuviese ya de una edad bastante avanzada.

${ }^{7}$ ABNB: EP, Gaspar Núñez, 14. 09. 1612: 578-581; Juan de Loarte, 11. 06. 1621: 94.
} 


\section{Paola A. Revilla Orías}

Ahora bien, no cabe duda que manumitir un esclavo en edad productiva -variable pero usualmente entre los 18 y 50 años- era sinónimo de perder el control legal directo sobre su persona y servicio, la suma invertida en su adquisición y los ingresos que podía generar en diferentes actividades a las que el amo pudiera encomendarlo. En La Plata como en otras ciudades coloniales fue usual el trabajo de esclavos en distintas actividades del comercio informal, así como el alquiler temporal de su fuerza laboral a terceros dentro del artesanado y en la agricultura en las chacras. De actuar en interés propio o de sus familiares, el amo bien podía considerar más conveniente la venta del esclavo que su manumisión graciosa. No obstante, en La Plata como en otras ciudades, los esclavos fueron manumitidos en mayor proporción siendo aún jóvenes y sobre todo niños (Duharte, 1989: 145; Schwartz, 1974: 616; Johnson, 1979, Proctor, 2006: 313). Entre las razones puede estar el vínculo afectivo desarrollado con los amos y amas, en particular cuando se trataba de esclavos heredados (Johnson, 1979: 271). Pero también y sobre todo porque no pocas de estas manumisiones tuvieron como trasfondo la negociación monetaria y laboral encaminada por los esclavizados y sus parientes.

La relación cotidiana amo-esclavo, que no debe ser pensada únicamente en clave de oposición binaria, pudo generar afectos profundos. El eclesiástico Juan de Rueda señala en 1606 que manumitía a la hija de un año de su esclava Magdalena: "por el amor que le tiene y porque se crió en su casa". ${ }^{8}$ Hay casos de amos que manumiten a los hijos pequeños de sus esclavas bajo el argumento de la gratitud a su servicio. Así, en 1565 el capitán Juan Ortiz de Zárate libera al hijo de seis años de su esclava Ana: "por los buenos servicios que ha hecho su madre", aunque no la liberó a ella. ${ }^{9}$ Algunos de estos niños bien pudieron ser hijos no reconocidos de los amos. ${ }^{10}$

Se podría pensar que aquellos amos que disfrutaban de cierta holgura económica y que no dejaban descendencia eran más proclives a manumitir a sus esclavos antes de morir, pero no es posible generalizar. Pudo también mediar el deseo católico de expiación de culpa y el de ganar indulgencias para el alma antes de partir. De cualquier manera, aunque hay situaciones en que los amos se encuentran testando en su lecho de muerte, en la mayoría no es el caso. Tampoco hay que olvidar que las expresiones desinteresadas de benevolencia y caridad otorgaban un brío especial a la imagen pública del amo.

La imagen del liberto también podía verse beneficiada cuando el amo aclaraba por escrito que la libertad era concedida como premio a la conducta de buen cristiano de su sirviente ${ }^{11}$. Una buena recomendación podía jugar mucho a favor del liberto cuando buscase trabajo en la ciudad. Al liberar a su esclava María de 20 años en 1564, el ya mencionado Juan Ortiz de Zárate señala que prueba de la virtud de la joven era que se había casado con un calcetero español; lo que para la mentalidad

\footnotetext{
${ }^{8}$ ABNB: EP, Gaspar Núñez, 21. 08. 1606, fs. 669-670.

${ }^{9}$ ABNB: EP, Lázaro del Águila, 06. 11. 1566, fs. 675-676.

${ }^{10}$ Frank T. Proctor (2006: 321 ) ya ha advertido sobre el gesto paternalista para con los libertos como una máscara de la paternidad real.

${ }^{11}$ Véase, por ejemplo: ABNB: EP, Juan de Loarte, 17. 05. 1607, f. 163.
} 


\section{La libertad conquistada: Consideraciones sobre manumisión, gratitud y coerción en Charcas colonial (siglos XVI-XVIII)}

de la época significaba una apuesta a la mejora de la calidad personal. ${ }^{12}$ Además, los argumentos de manumisión graciosa no solo hacen eco de voluntades y sentires personales concretos; sino que a veces son fórmulas jurídicas recurrentes que los escribanos veían apropiado sentar por escrito por costumbre o para favorecer a las partes.

Las concesiones de libertad pudieron ser también gracia de terceros, caso en el que el amo recibía a cambio el importe del esclavo. El arzobispo de Charcas, fray Domingo de Santo Tomás dispuso antes de morir en 1570 que 300 pesos de sus bienes fueran a cubrir el costo de Juan, esclavo cocinero de Sebastián León ${ }^{13}$. Su albacea, Baltasar de Villalobos, ejecutó la disposición. Lo encontramos tres años después emitiendo cartas de libertad para los esclavos Rodrigo y Ana, tal cual había dispuesto el finado fraile. ${ }^{14}$

La invitación aquí es a una apertura crítica a la diversidad de situaciones, intereses y sentires que pudieron llevar a la concesión de la libertad legal a los esclavos en Charcas. Sus mecanismos no siempre pueden entenderse a cabalidad a partir del dato de una sola acta notarial, la que puede incluso llevar a una lectura errada del proceso manumisorio llevado en marcha por amos y esclavos.

\section{¿Gracia o coartación? aspectos velados de la manumisión}

Cuando además de la descripción del catálogo de escrituras públicas -de haberlo-, los historiadores miramos el texto mismo del acta o la cláusula testamentaria libradora, nos encontramos por ejemplo con que parte de las manumisiones graciosas no son de efecto inmediato, sino que vienen condicionadas. De hecho, es el caso del 28\% (18 casos) del total de las manumisiones sistematizadas en la muestra revisada para La Plata entre 1560 y 1630. Así, la concesión de libertad pudo generar nuevas y variadas situaciones dependencia.

Estos compromisos de liberación implicaban que el amo no emitiría carta de libertad sino cuando el esclavo hubiese cumplido lo pactado. El vecino potosino Alberto de Escóbar decidió por ejemplo el 3 de agosto de 1577 otorgar la libertad a su esclavo Bartolomé, que le había servido durante 12 años "bien y fielmente". El detalle está en que esta debía hacerse efectiva solo cuatro años después. ${ }^{15}$ Los plazos estipulados por los amos van hasta los 10 años en el caso charqueño. El riesgo de estos acuerdos es que podían disolverse en el tiempo ante cualquier cambio de opinión del amo, generando la revocatoria de la cláusula manumisoria. Stuart B. Schwartz (1974: 632) ha advertido sobre este fenómeno y lo lee como un gesto socialmente aceptado que revela la resistencia del amo a dejar de tener control sobre quien fuera su esclavo. Lo cierto es que no había garantía real para el esclavo

\footnotetext{
12 ABNB : EP, Lázaro del Águila, 29. 04. 1564, f. 187.

${ }^{13}$ ABNB: EP, Juan Bravo, 02. 08. 1570, fs. 192-195.

${ }^{14}$ ABNB: EP, Juan Bravo, 03. 10. 1573, fs. 651-652.

${ }^{15}$ ABNB: EP, Juan García Torrico, 03. 08. 1577, fs. 375-376.
} 


\section{Paola A. Revilla Orías}

sino hasta que adquiría el documento escrito que probaba su nueva condición de liberto: la carta de libertad (Belmonte, 2005: 19; Pérez Morales, 2017: 520; Dimunzio, 2007) ${ }^{16}$.

Entre la diversidad de situaciones que generó la manumisión condicional pudo pasar que el requisito fuese servir a una tercera persona por cierto tiempo o hasta su fallecimiento. Miguel Gutiérrez dispuso en su testamento dado en La Plata en 1688 que, de servir al racionero de la catedral hasta su muerte, su esclavo, el mulato Félix, quedaría libre. ${ }^{17}$ Este no devenía por tanto propiedad del racionero, pero sería tratado todo ese tiempo como esclavo.

Amos y esclavos también podían acordar la entrega de un monto de dinero para hacer efectiva la manumisión. Como es sabido, comprar su libertad era un derecho consuetudinario (Lucena Salmoral, 1999: 358; Portilla, 2015: 99). La práctica ponía en cuestión la propia institución esclavista, trasluciendo que la esclavitud no estaba determinada por la naturaleza de las personas, sino que reposaba en una relación comercial. Así debe entenderse que en 1599 el español Diego García se haya comprometido a liberar a su esclava Antonia: "el día que por su libertad pagara 250 pesos" a su albacea. ${ }^{18}$ Por su parte, en su lecho de muerte en 1583 el deán de la catedral Francisco Urquizo dispuso dejar libre a su esclava Ana: "si pagara 300 pesos ensayados"19. Estos acuerdos reflejan el rol activo de los esclavos en La Plata en las negociaciones para conseguir su libertad. Eduardo Franca Paiva (en Moritz \& Dos Santos, 2018: 95) ya advirtió que las manumisiones fueron en buena medida más que concedidas, negociadas entre amos y esclavos. En el caso boliviano, Alberto Crespo (1995: 77) ha afirmado a mediados del siglo XX que pocos esclavos pudieron recurrir a este mecanismo en las ciudades de Charcas, donde el fenómeno apenas aparece documentado. Nuestra pesquisa para el caso de La Plata comprueba que no es así y que, como en otras regiones, las manumisiones por coartación fueron más frecuentes que las graciosas (Schwartz, 1974; Bowser, 1977; Trazegnies, 1981; Johnson, 1997; Navarrete, 2005; Belmonte, 2005; Portilla, 2015; De la Fuente, 1990). La revisión exclusiva de las descripciones de catálogos puede llevar a tildar de merced desinteresada manumisiones que en realidad fueron coartación.

Lo más sobresaliente en el caso de La Plata es que este tipo de casos se dejan ver desde pocas décadas después de fundada La Plata (1538), haciendo eco de un dinámico mercado laboral en el que los esclavizados pudieron generar ingresos de importancia. ${ }^{20}$ Así, cuando en 1587 Pedro Álvarez concede carta de libertad a su

\footnotetext{
${ }^{16}$ Letícia Gregório (en Secreto \& Freire, 2018: 129-155) refiere que en el caribe francés del siglo XIX el trámite de la carta de libertad ante las autoridades coloniales era tan costoso que muchos amos daban solo la "aforria legal" que sumía a los manumitidos en situaciones de libertad muy precaria y ambigua. Véase también: Chalhoub, 2015; Scott \& Hébrard (2012).

${ }^{17}$ ABNB: Expedientes Coloniales (EC) 1686, 24.

18 ABNB: EP, Gaspar Núñez, 24. 05. 1599, fs. 972-979.

${ }^{19}$ ABNB: EP, Juan García Torrico, 01. 01. 1583, fs. 507-527.

${ }^{20}$ A fines del siglo XVI un esclavo en La Plata costaba entre 461 y 721 pesos corrientes, es decir, una media de 562 pesos siendo las mujeres más costosas. Pedro Ramírez del Águila (1639: 74) indica hacia 1639 que el costo promedio era entre 500 y 600 pesos y lo hemos comprobado revisando las transacciones del periodo
} 


\section{La libertad conquistada: Consideraciones sobre manumisión, gratitud y coerción en Charcas colonial (siglos XVI-XVIII)}

esclava la negra Juana, sabemos que estaba pagándole: "600 pesos de plata ensayada”. ${ }^{21}$ Del mismo modo, detrás de la retórica de concesión de libertad por los buenos servicios que en más de 50 años le entregó la esclava Lucía a su ama, la vecina doña Catalina Zurbarán, queda inscrito que aquel día de 1586 le estaba dando 300 pesos a cambio. ${ }^{22}$ Según el tipo de acuerdo, el dinero podía ser entregado por partes. La esclavizada Guiomar de 35 años empezó pagando 100 pesos a Diego de Salazar al que aún le debía 450 en $1566 .{ }^{23}$ Era usual firmar los acuerdos una vez que se ha realizado el primer pago. ${ }^{24}$

El monto podía ser ocasionalmente mayor si el esclavizado había por ejemplo aprendido algún oficio; o menor en caso de haber sufrido alguna enfermedad. De mediar la voluntad del amo, este podía rebajar el precio. ${ }^{25}$ Así, Francisco de Vitoria, rector del colegio de la Compañía de Jesús en La Plata acordó manumitir a Antón López, esclavo de 40 años en 100 pesos, muy por debajo de su precio en el mercado local ${ }^{26}$. Cuando amo y esclavo no llegaban a un acuerdo podían pedir intervención de la justicia para llamar a tasadores neutrales (Aguirre, 1995: 103).

Los acuerdos de pago eran una garantía para los esclavos, ya que mientras terminaban de cancelar su importe el amo no podía venderlos ni trasladarlos del espacio donde residían (Klein \& Vinson, 2008). En algunos documentos platenses estos incluso ya figuran como libertos o coartados, categoría intermedia entre la esclavitud y la libertad (Schwartz, 1974: 628). ${ }^{27}$ No faltaron amos que, cambiando de opinión, intentaron enajenar a los esclavos, incluso habiendo recibido algún pago previo. También sucedió que los amos entregaron carta de libertad a sus esclavos después del primer pago, firmando un pagaré por lo restante. La esclava Beatríz Ana Palla por ejemplo, firmó en 1577 una obligación de pago de 457 pesos a Carlos Vendres: "por la carta de libertad que le otorgó". ${ }^{28}$ Esta situación delataba no solo buena voluntad, sino la necesidad del amo de un adelanto de dinero. Como sucedió en otras regiones (Belmonte, 2005: 5; Díaz, 2002: 71), en La Plata la vida de muchos amos que se encontraban desposeídos, solo o enfermos dependía de los ingresos que generaba el trabajo de sus esclavos.

Dicho sea de paso, el trabajo doméstico no debe circunscribirse al espacio de la casa del amo ni descarta el trabajo en las calles (Proctor, 2006: 325), actividad que en La Plata podía reportar no poco beneficios. El esclavo de Inés Tortoles por ejemplo le ofreció sin mucha dificultad nada menos que 1500 pesos por su libertad en 1597. Su

\footnotetext{
entre 1560 y 1630 . Para una relación de precio, sexo y edad de los esclavos en este periodo en esta ciudad véase: Revilla, 2020.

${ }^{21}$ ABNB: EP 1587, Jerónimo de Porres, 07. 08. 1587, fs. 594-599.

${ }^{22}$ ABNB: EP, Francisco de Tovar, 28. 08. 1586, f. 145.

${ }^{23}$ ABNB: EP, Lázaro del Águila, 25. 06. 1566, f. 339.

${ }^{24}$ Rafael Duharte (1989: 107) refiere que, al menos en Santiago de Cuba, estaba normado que las cuotas se formalicen sobre una base de 50 pesos.

${ }^{25}$ Esta rebaja pudo estar condicionada a que el esclavo no busque otro amo (Postigo, 2005: 6).

${ }^{26}$ ABNB: EP, Diego Sánchez, 26. 12. 1603, fs. 921-922. Sobre manumisión vinculada a los precios de los esclavos en el mercado véase Belmonte, 2005; Duharte, 1989: 158 y Johnson, 1979.

27 Véase, por ejemplo: ABNB: EP, Juan García Torrico, 31. 08. 1580, fs. 221-222.

${ }^{28}$ ABNB: EP, Francisco García, 08. 02. 1577, f. 691.
} 


\section{Paola A. Revilla Orías}

nombre era Domingo Bohío, era oficial carretero, carpintero y labrador. ${ }^{29}$ Eso sí, dados los fuertes prejuicios de la mentalidad colonial, la inversión de la relación de dependencia económica no alteraba el trato del amo al esclavo como servidumbre. Otro elemento importante para entender la habilidad de gestión de recursos que hicieron los esclavizados es que lograron acuerdos que no involucraban únicamente dinero sino también servicios y no siempre manuales, a cambio de libertad. ${ }^{30}$ Así, el esclavo Francisco Perero se comprometió en 1551 con los franciscanos de La Plata a enseñar a leer a "muchachos mestizos" que acudían al convento hasta completar con su servicio los 420 pesos que debía a la Orden por su libertad. ${ }^{31}$ Sin duda, estos procesos manumisorios por coartación dependieron de las condiciones de esclavitud en que se encontraba cada persona. En La Plata como en Lima, Buenos Aires (Aguirre, 1995; Hünefeldt, 1992: Johnsonn, 1979: 275) y en otras urbes coloniales, los esclavos con oficios de artesanos y algunas mujeres de trabajo estipendiario tenían más posibilidades que otros de pagar por su libertad aunque no tuviesen apoyo familiar. Los demás, en particular los hombres adultos bozales, podían pasar la vida en el intento.

Estaban también aquellos que, no pudiendo alcanzar a reunir el precio de su coartación, optaron por el endeudamiento con terceros que hacían de prestatarios. Como recuerda Bernand Lavallé (1999: 222), las Siete Partidas preveían que si el esclavo encontraba quien pudiera pagar su precio, el amo no podía oponerse. Los esclavos devolvían lo invertido en dinero o en trabajo al "rescatador", como se lo llamaba en Charcas. Así debe entenderse que una vez entregada la carta de libertad al esclavo Francisco Salazar, devenido horro el 23 de julio de 1565, el mismo día aparezca firmando una obligación de pago a favor de Diego Sánchez: "procedente de un préstamo de dinero para comprar su libertad de Antonio García". ${ }^{32}$ No faltan tampoco los libertos que hacen de prestamistas para que esclavos conocidos y amigos suyos adquieran su libertad. El ya referido Domingo Bohío prestó en 1604 y por 6 meses, 76 pesos al moreno libre Antón López para terminar de pagar su libertad a la Compañía de Jesús. ${ }^{33}$ Y es importante subrayar que el apoyo no vino únicamente de la actitud caritativa de los amos, sino también de parientes y amigos de distinto origen y condición, íntimamente involucrados con los deseos de libertad de los esclavizados ${ }^{34}$.

Varias estrategias y esfuerzos prácticos fueron encaminados por parejas de condición legal mixta en La Plata, en que la parte libre buscó ayudar a la esclava a ir

\footnotetext{
${ }^{29}$ ABNB: EP, Agustín de Herrera, 25.01.1597, fs. 1-5.

${ }^{30}$ Stuart Schwartz (1974: 626) alude a otra forma de pago de la libertad personal -y no la menos curiosaen Brazil que no hemos documentado aún para Charcas, mediante la sustitución con otro esclavo.

${ }^{31}$ ABNB: EP, 28. 01. 1551, f. 383.

32 ABNB: EP, Francisco Logroño, 23. 07. 1565, f. 345.

${ }^{33}$ ABNB: EP, Diego Sánchez, 09. 01. 1604, f. 947.

${ }^{34}$ Como puntualiza Magdalena Candioti (en Secreto y Freire, 2018: 151) los libertos fueron considerados "receptores de una gracia", de un favor, y esta lógica movió las manumisiones hasta el siglo XIX más que la abolicionista.
} 


\section{La libertad conquistada: Consideraciones sobre manumisión, gratitud y coerción en Charcas colonial (siglos XVI-XVIII)}

pagando por su libertad. Así, se aseguraban que sus hijos nacieran libres. ${ }^{35}$ Cuando ambos eran esclavos intentaban encontrar un intermediario para apoyar la manumisión ${ }^{36}$. En otro momento he presentado el caso de la familia cacical que ayudó al esclavo Clemente a comprar su libertad en Panacachi, La Paz (Charcas) del siglo XVIII (Revilla, 2019). Padres, madres y abuelos(as), esclavizados y libertos, juntos o por separado realizaron las gestiones necesarias para comprar la libertad de sus hijos y nietos. ${ }^{37}$ A mediados del siglo XVII el abuelo liberto Sebastián Quiculo ahorró de lo que le daba una pequeña chacra de trigo y maíz hasta liberar a su nieta, Ana. ${ }^{38}$ Hijos y nietos de esclavos aparecen también apoyando la libertad de sus mayores. El mulato libre Juan Quijada se prestó 250 pesos del canónigo Pedro López para manumitir a su padre, el negro Juan, quien recibió carta de libertad el mismo día de 1586 que su hijo contrajo la deuda. ${ }^{39}$

A pesar de esta realidad, los escribanos suelen usar fórmulas retóricas que hacen ver estos acuerdos como merced del amo para proteger su buen nombre. La sola búsqueda de libertad de un esclavo sin previo acuerdo con el amo era tenida por un agravio, una muestra de ingratitud, casi una injuria. La historiografía debe hacerse responsable de no reproducir mecánicamente esta construcción discursiva que opaca el trasfondo de las habilidades de que hicieron prueba los esclavizados en la consecución de su libertad legal. La coartación debe ser evaluada como lo que fue, un proceso muchas veces largo y complejo, disímil según las condiciones de vida de una y otra persona. Gestionada por los esclavos, implicó una serie de negociaciones que pudieron arribar a buen puerto.

Como se ha dicho, en ocasiones, una sola escritura no permite entender a cabalidad el tipo de procedimiento de liberación frente al que estamos. Es necesario cruzar los datos de las obligaciones de pago con los de las cláusulas testamentarias y de las cartas de libertad para saber en qué medida hablamos de manumisión graciosa, condicional o de coartación, también llamada automanumisión. El estudio exhaustivo de las actas notariales es un trabajo lento y dificultoso, pero mueve a evitar lecturas incompletas de la realidad.

\section{La vulnerabilidad del manumitido}

Un aspecto que merece atención es la delicada y no poco ambigua realidad jurídica del manumiso, coartado, liberto u horro en escenario colonial. Su condición fue un lugar de paso de durabilidad variable y muchas situaciones pudo poner en peligro

\footnotetext{
35 Véase algunos ejemplos en: ABNB: EP, Gaspar Núñez, 08. 02. 1608, fs. 45-50v; Juan García Torrico, 06. 12. 1584, fs. 800-801. Eugenia Bridikhina (1994) documenta este tipo de casos para el siglo XVIII en la ciudad de La Paz en Charcas.

${ }^{36}$ Véase: ABNB: EP, Juan García Torrico, 11. 01. 1580, fs. 208-209; Juan García Torrico, 31. 01. 1580, fs. 230-234.

${ }^{37}$ Véase: ABNB: EP, Juan de Loarte, 05. 10. 1623, fs. 339-341; Agustín de Herrera, 15. 04. 1625, fs. 143144.

${ }^{38}$ ABNB: EC 1648, 30.

${ }^{39}$ ABNB: EP, Jerónimo de Porres, 16. 02. 1587, fs. 46-47.
} 


\section{Paola A. Revilla Orías}

la libertad legal adquirida. Por una parte, están aquellos que habiendo sido manumitidos por sus amos se encontraron con la negativa de los herederos de aceptar la voluntad testamentaria. ${ }^{40}$ En estos casos podían entablarse litigios largos y costosos en los que los esclavizados debían velar cuidadosamente por su defensa. ${ }^{41}$ Un ir y venir de escritos les quitaban energías tratando de demostrar que la manumisión resultaba de la buena relación con el amo, de la lealtad de su servicio; así como defender el conocimiento de la existencia de la cláusula testamentaria que los liberaba. Los más próximos solían estar presentes con la familia cuando el escribano anotaba las disposiciones junto a la cama del amo.

La carta o escritura de libertad se reveló indispensable para que los libertos no corran el riesgo de ser re esclavizados. Ampararse únicamente en la voluntad o promesa verbal del amo fallecido o en la sola cláusula testamentaria se revelaba insuficiente frente a las ambiciones de terceros endeudados o empobrecidos, interesados en vivir del trabajo de manumitidos sobre los que creían tener derechos. La pérdida del documento pudo ser determinante. Así, Pero Terrazas cayó en desesperación en 1761 en Sacaba (Cochabamba) cuando el apoderado de su difunto amo perdió la carta que había puesto: "en el bolsillo izquierdo de mi chupa y habiendo caminado todo el día pasando muchos vados de un río" para llegar a La Plata a presentarla. El tribunal de la Audiencia no consideró la prueba verbal suficiente. ${ }^{42}$

La falsificación de documentos era otro riesgo al que muchos esclavizados iletrados tuvieron que enfrentarse. Existen varios casos de herederos y albaceas acusados ante los tribunales platenses de esconder e incluso romper los documentos garantes de la manumisión. Y lo hicieron a pesar de que la concesión no les otorgaba derechos de posesión sobre el esclavo (Lucena Salmoral, 1999: 358). A la mulata Marcela Velázquez Ovando por ejemplo, le habían quitado los papeles de una defensa que sostenía con dificultad en $1630^{43}$. El heredero de doña María Tejerina, residente en Pilaya (La Plata), directamente quemó el testamento de su madre para que no constara que sus esclavos habían sido liberados. ${ }^{44}$

Pasaba también que los amos tenían dificultad de encontrar la escritura que formalizaba la posesión de sus esclavos, el llamado título de dominio. Don Esteban Quintana, dueño de una hacienda en Mojocoya, señalaba preocupado en 1797: me es difícil hallar las escripturas" de su esclavo huido, el negro José Benito. ${ }^{45}$ En el caso de los bozales los amos debían tener la declaración firmada de quien los trajo desde África; en el de los criollos, la partida de bautismo en Charcas y, en todo caso, la

\footnotetext{
${ }^{40}$ Para el caso chileno véase: Mejías, 2010.

${ }^{41}$ Para facilitar el recurso a la justicia el virrey Francisco de Toledo había implementado un sistema de asesoría legal del que hicieron amplio uso indígenas y afrodescendientes esclavizados desde el siglo XVI. Véase: Tamar Herzog, 1996.

42 ABNB: EC 1761, 9. A pesar de esto, Ots Capdequí (1945: 143) puntualiza que la promesa contractual como alegato no carecía de legitimidad y que tenía carácter de obligatoriedad sin que fuese necesaria una construcción jurídica al respecto.

${ }^{43}$ ABNB: EC 1630, 11.

${ }^{44}$ ABNB: EC 1674, 8.

${ }^{45}$ ABNB: EC 1797, 16, f.1.
} 


\section{La libertad conquistada: Consideraciones sobre manumisión, gratitud y coerción en Charcas colonial (siglos XVI-XVIII)}

escritura de compra-venta. Si el esclavo había sido comprado y vendido varias veces, el último amo debía tener la constancia de todo el proceso, lo que no siempre ocurría y mucho menos en mercados de reventa como los charqueños, con fuerte impronta de contrabando.

Otro escenario de pleito recurrente tenía lugar cuando se le negaba la liberación al esclavo a pesar de haber cumplido con la condición que el amo le había señalado. Esto podía deberse a la ya mencionada resistencia a dejar de tener control sobre quien fuera asimilado como esclavo de la casa. $S$ frecuente ver a herederos y albaceas argumentando la existencia de codicilos revocatorios de las cláusulas manumisorias. ${ }^{46}$ Los mismos pudieron existir o no, haber sido firmados por los amos agonizantes en su lecho de muerte incluso ser escritos fraudulentos. A Juan Vendeli, oficial herrero y sirviente doméstico, le ocurrió que habiendo servido al esposo de su ama hasta su fallecimiento como convenido antes de ser manumitido, se encontró en 1669 con que el albacea lo había vendido a la Compañía de Jesús. ${ }^{47}$ El jesuita que se preciaba de ser su nuevo amo, Joseph del Castillo, no dudó en alegar que incluso si le hubiesen concedido la libertad ya la tenía perdida por ingratitud dada su conducta ante los tribunales. La gratitud al amo manumisor debía demostrarse con acciones y era un argumento válido en la época, denotaba que el liberto sabía conducirse en policía. ${ }^{48}$ El caso es que Juan fue además acusado de robo para complicarle la defensa. A pesar de todos estos contratiempos, asistido en su demanda por el defensor de pobres Álvaro Pinto, consiguió ganar el pleito. La defensa de la libertad personal o de la de algún pariente manumitido es sin lugar a dudas el alegato más reiterado en los procesos judiciales iniciados por afrodescendientes en Charcas a lo largo del período colonial. Es importante destacar como han hecho varios estudios los últimos años, la familiaridad de los esclavizados con el sistema judicial ${ }^{49}$. Asesorados por abogados y escribanos, realizaron cálculos de sus opciones según los condicionamientos sociales y las brechas del sistema (Sweet \& Nash, 1987: 15; Aguirre, 1995: 22; Bernand, 2002b: 102; Arrelucea, 2007). La violencia del afán por legitimar el poder y control sobre la población manumitida pudo no tener reparos en la vulnerabilidad de hijos y hermanos de sangre (Pita Pico, 2016: 36). La mulata Andrea González era hija de la esclava de su amo, un español residente en La Plata. ${ }^{50}$ Había crecido: "en pacífica posesión de libertad" hasta que a sus 22 años, en 1677, los herederos, sus hermanos, intentaron venderla junto a la chacra en la que residía. Si bien sus amigos (en su mayoría afrodescendientes e indígenas) la apoyaron como testigos, refiriendo que su padre la sentaba a la mesa con él y la: "nombraba de hija y niña y otras palabras amorosas", al no poseer

\footnotetext{
46 Véanse algunos ejemplos en: ABNB: EC Ad 1, 1672, 3, f. 2; 1675, 21. Sobre la figura de los codicilos coloniales remito a: Ots Capdequí, 1945: 119.

${ }^{47}$ ABNB: EC 1669, 25b.

${ }^{48}$ Los esclavos manumitidos por coartación tenían menor responsabilidad de agradecimiento al amo, como sostiene Belmonte, 2005: 14.

49 Véase González, 2007; Ogass Bilbao, 2009; San Martín Aedo, 2007; Trazegnies, 1981; Aguirre, 1995; Arrelucea, 2007; Mallo, 2004; Chávez, 2001.

${ }^{50}$ ABNB: EC 1677, 2.
} 


\section{Paola A. Revilla Orías}

escritura de libertad, poco pudo hacer para defender su libertad personal. A su turno, el mulato Miguel Cabello tuvo que enfrentarse como hijo natural ante el tribunal de La Plata contra sus familiares más cercanos en $1684 .{ }^{51}$ Su padre lo había encargado a su abuela antes de morir, pidiéndole le enseñase a leer y escribir. Alegó que su padre quería que lo: "dejasen estar libremente arrimado al amparo y abrigo del heredero que me pareciere a mí, y quien me tuviese buen afecto y tratase como a pariente y a persona libre". Su defensa fue bien llevada, prosperó y la libertad le fue reconocida.

Los vaivenes judiciales no solo dan cuenta de los intereses y preocupaciones de amos y libertos. Las propias autoridades mostraban temor prejuicioso ante el ejercicio de la libertad por parte de los manumitidos (Schwartz, 1974: 633). Las medidas tomadas desde el siglo XVI iban incluso a prohibirles la autonomía de residencia. El virrey Toledo había dejado estipulado que: "ningún negro ni mulato horro pueda tener casa por sí, si no fuere oficial y tuviere tienda pública del dicho oficio".52 Y esta mirada se prolongó en el tiempo. Analizando la realidad de los libertos en Brazil de inicios del siglo XIX Beatriz G. Mamigonian (en Moritz \& Dos Santos, 2018: 77) advierte: "a sociedade imperial não considerava dignas de exercer a liberdade com autonomia"53. A pesar de esta disposición, la documentación muestra que los libertos y libertas de distinta ocupación adquirieron toda suerte de bienes y que vivieron en casas propias mientras pudieron pagarlas. ${ }^{54} \mathrm{El}$ panorama era sin duda más difícil para los que no tenían recursos. El tribunal no accedió ni siquiera a dar curso a la demanda de libertad de Juan Angola en 1662.55 Consideró que: "en las Indias no es favorable la libertad, ansí se ha de restringir lo posible porque los mulatos y negros libres en este reino no ser bien de otra cosa que de hurtar y hacer delitos". ${ }^{56}$ Juan se había aferrado a la promesa de su amo y amigo Andrés Marín, para quien había trabajado durante 20 años en su hacienda de Maragua.

Pasó también que los libertos que no tenían ocupación ni señor a quien servir pudieron ser encomendados temporalmente a vecinos de la ciudad a cuya casa y servicio se arrimaban, tal como ocurrió con indígenas cautivos de tierras bajas a quienes se tenía por "infieles rescatados" inhábiles para conducirse en libertad. La tutela sobre sus personas debía ser temporal, pero pudo extenderse por tiempo indefinido. La sociedad legitimaba el hecho de que el dejar de ser esclavo no implicaba necesariamente el abandono de ciertas responsabilidades con los ex amos (Belmonte, 2005: 13; Duharte, 1989: 113). Se esperaba de los manumitidos el trabajo humilde y la gratitud al señor, entendida dentro de los valores paternalistas

\footnotetext{
${ }^{51}$ ABNB: EC 1684, 3.

52 Ordenanzas del virrey don Francisco de Toledo, Cuzco, 1572, tit. XXII: “De los negros”. En Relaciones de los virreyes y Audiencias, 1867, t. I, pp. 91-93.

${ }^{53}$ Véase también: França Paiva, 1995: 49 para Minas Gerais del siglo XVIII.

${ }^{54}$ Véase a este respecto Revilla, 2018 y de Lofstrom, 2010.

${ }^{55}$ A pesar de que la cédula real dada en Madrid el 15 de abril de 1540 que determinaba: "Que las Audiencias oigan y provean justicia a los que proclamaren la libertad”. Recopilación de Leyes de Indias, 1681, lib. VII, tít. 5, ley 8.

${ }^{56}$ ABNB: EC 1662, 35.
} 


\section{La libertad conquistada: Consideraciones sobre manumisión, gratitud y coerción en Charcas colonial (siglos XVI-XVIII)}

imperantes, a cambio de la protección brindada. Algunos pudieron sentirla y esto los llevó a permanecer en casa del señor, a su servicio, a pesar de la autonomía que fueron adquiriendo en su desenvolvimiento en la urbe. A otros les fue imposible no ejercer resistencia frente a los abusos y la coerción laboral a que estuvieron expuestos sabiéndose legalmente libres. En ocasiones, consolidada su emancipación de aquella relación de dependencia impuesta, los libertos replicaron el modelo de explotación experimentado, adquiriendo a su turno servidumbre libre y esclava. Los códigos de conducta que sostenían el andamio de la dominación colonial habían sido fuertemente internalizados y naturalizados por la población en la convivencia.

\section{Conclusiones}

La manumisión en sus diferentes formas fue mucho más que un hecho administrativo puntual. Se trató de un proceso complejo y largo al que no todos los esclavizados pudieron acceder y, los que lo hicieron, mostraron notable habilidad de gestión de recursos materiales y humanos para conseguirla. Es importante destacar esto ya que no siempre se trató de una merced del amo al sirviente. La propia retórica de las actas notariales y de las cláusulas testamentarias dejan pensar que era así cuando en realidad mediaba detrás un acuerdo condicionante o el pago por parte del esclavizado.

Contrario a lo que se ha dicho para el caso charqueño, hubo una importante proporción de esclavos y esclavas que gestionaron su manumisión de diversas formas y consiguieron el apoyo para pagarla cuando fue necesario. El tiempo, que no todos tuvieron, jugó un papel fundamental para conseguir los recursos y formalizar la carta de libertad, a cuyo carácter de prueba imprescindible se ha hecho referencia. Los esclavizados que tenían un oficio o negocio, una relativa buena relación con sus amos y sólidas redes afectivas pudieron manumitirse más rápidamente en La Plata. Otros, intentaron ampararse en promesas y condiciones varias que amos, albaceas y herederos no siempre respetaron. Aún así y desde esa vulnerabilidad supieron dirigirse a los tribunales a pelear sus causas de liberación. La libertad legal era sinónimo de mayor autonomía de movimiento, de poder decidir dónde y con quién vivir, para quien trabajar. No obstante, la condición jurídica intermedia de liberto(a), de duración variable en la designación de las personas, pudo ser un fuerte obstáculo para el ejercicio de la autonomía plena del manumitido. Se esperaba que este demuestre gratitud hacia la autoridad de corte paternalista de su ex amo, lo que lo llevó a seguirle sirviendo e incluso a no abandonar la casa donde había sido esclavizado. Las disposiciones de las autoridades locales para los horros muestran la desconfianza predominante con la que fueron tratados. Un telón de fondo para quienes quisieron rentabilizar a su favor la fuerza laboral de personas a las que no les había sido fácil conseguir su libertad legal y que se veían conminadas a luchar por preservarla. En este sentido, vivieron una realidad muy similar los indígenas de tierras bajas que llegaron cautivos a las ciudades de Charcas. 


\section{Paola A. Revilla Orías}

Si bien es posible que afectos profundos se hayan desarrollado entre amos y esclavos, también es cierto que el tipo de relación que tuvieron difícilmente se sustrajo de la lógica de relacionamiento prevalente en la sociedad colonial. Un esclavizado tenía derecho a denunciar abusos, a comprar su libertad o a gestionar quien la pague, pero esto no hablaba bien del ejercicio de autoridad de su amo. Un liberto pudo llegar a generar más ingresos que su amo, ocuparse de mantenerlo y tener más redes familiares que él, pero no se libró del estigma de vinculado a su condición pasada. Los parámetros de la dominación colonial estaban tan internalizados y naturalizados en la interacción social, que no faltaron los manumitidos que reprodujeron el ejercicio de autoridad que habían experimentado cuando tuvieron los recursos para hacerse de servidumbre de distinto origen.

\section{Bibliografía}

Agia, M. (1604). Tratado que contiene tres pareceres graves en derecho. Lima: Antonio Ricardo.

Aguirre, C. (1995). Agentes de su propia libertad. Los esclavos de Lima y la desintegración de la esclavitud (1821-1854). Lima: PUCP.

Arrelucea, M. (2007). Lágrimas, negociación y resistencia femenina: esclavas litigantes en los tribunales. Lima 1760-1820. Summa Historiae (2) 2, pp. 85-102.

Belmonte P., J. L. (2005). Con la plata ganada y su próprio esfuerzo. Los mecanismos de manumisión en Santiago de Cuba, 1780-1803. Revista Del Grupo de Estúdios Afroamericanos 3, pp. 1-33.

Bernand, C. (2002a). Noirs esclaves et affranchis en Amérique ibérique. Clío. Fr. Recuperado de

http://www.clio.fr/bibliotheque/pdf/pdf noirs esclaves et affranchis en ameriqu e iberique.pdf

Boccara, G. La (eterna) vuelta del malón. Contemporaneidad y anacronismo de los indígenas en Chile y Argentina. Ponencia presentada en el coloquio La Conquista desde otras perspectivas. Bogotá: Instituto Colombiano de Antropología e Historia. Recuperado de https://www.youtube.com/watch?v=yjPzQQNDsDk

Bowser, F. (1977). El esclavo africano en el Perú colonial 1524-1650. México: Siglo XXI. 


\section{La libertad conquistada: Consideraciones sobre manumisión, gratitud y coerción en Charcas colonial (siglos XVI-XVIII)}

Bridikhina, E. (1994). La vida urbana de los negros en La Paz en el siglo XVIII. En Seminario de Antropología Histórica. Reunión anual de etnología. La Paz: Mundy Color, pp. 23-32.

Chalhoub, S. (2015). The Politics of Ambiguity: Conditional Manumission, Labor Contracts, and Slave Emancipation in Brazil (1850s-1888). International Review of Social History (60), 2, pp. 161-191.

Chávez, M. E. (2001). Honor y libertad. Discursos en la estrategia de libertad de una mujer esclava (Guayaquil a fines del período colonial). Gotemburgo: Departamento de Historia e Instituto Iberoamericano de la Universidad de Gotemburgo.

Combès I. y Saignes, T. (1991). Alter Ego. Naissance de l'identité chiriguano. París: EHESS / Cahiers de l'Homme.

Cortés A. V. (1990). La manumisión y la sociedad hispanoamericana". En F. Solano (coord.); Esclavitud y Derechos Humanos: La lucha por la libertad del negro en el siglo XIX. Actas del Coloquio Internacional sobre abolición de la esclavitud. Madrid: Consejo Superior de Investigaciones Científicas, pp. 33-42.

Crespi, L. (2000). Contrabando de esclavos en el puerto de Buenos Aires durante el siglo XVII. Complicidad de los funcionarios reales. Desmemoria. Revista de Historia, 26, pp. 119-120.

Crespo, A. (1995). Esclavos negros en Bolivia. La Paz: Juventud.

De la Fuente, García A. (1990). A alforria de escravos em Havana, 1601-1610: Primeira conclusões. Revista de Estudos econômicos, São Paulo (20), 1, pp. 139-159.

De Trazegnies, F. (1981). Ciriaco de Urtecho litigante por amor: Reflexiones sobre la polivalencia táctica del razonamiento jurídico. Lima: PUCP.

Díaz, R. A. (2002). ¿Es posible la libertad en la esclavitud? a propósito de la tensión entre la libertad y la esclavitud en la Nueva Granada. Historia Crítica (24), pp. 67-74.

Dimunzio, K. (2007). La libertad deseada, ¿la libertad lograda...? Las Cartas de Libertad otorgadas a los esclavos en Córdoba entre mediados del siglo XVIII y principios del siglo XIX. Anuario de la Escuela de Historia (5): 165-181.

Duharte J., R. (1989). Apuntes sobre la manumisión de esclavos en Santiago de Cuba. Secuencia. Revista de Historia y Ciencias Sociales 13, pp. 106-116. 


\section{Paola A. Revilla Orías}

Fanon, F. (1961). Los concenados de la tierra. J. Campos (trad.); México: Fondo de Cultura Económica.

França Paiva, E. (1995). Coartaçaões e alforrias nas Minas Gerais do século XVIII: as posibilidades de libertação escrava no principal centro colonial. Revista de História (133): 49-57.

González, C. (2007). En busca de la libertad: la petición judicial como estrategia política. El caso de las esclavas negras (1750-1823)". En T. Cornejo \& C. González (eds.); Justicia, poder y sociedad: recorridos históricos. Chile, siglos XVIII-XXI. Santiago de Chile: Universidad Diego Portales, pp. 57-83.

Hanke, L. (1956). The imperial city of Potosí: an unwritten chapter in the history of Spanish América. Sucre: Universidad de San Francisco Xavier.

Herzog, T. (1996). Mediación, archivos y ejercicio: Los escribanos de Quito (siglo XVIIXVIII). Frankfurt: Vittorio Klostermann.

Johnson, L. (1979). Manumission in Colonial Buenos Aires, 1776-1810. Hispanic American Historical Review (59), 2, pp. 258-279.

Klein, H. S. y Vinson, B. (2008). La esclavitud africana en América Latina y el Caribe. Lima: IEP.

Lucena Salmoral, M. (1999). El derecho de coartación del esclavo en la América Española. Revista de Indias (59), 216, pp. 357-374.

Mallo, S. (2004). Experiencias de vida, formas de trabajo y búsqueda de libertad". En H. van Hooff (coord.); La ruta del esclavo en el Río de La Plata: Su historia y sus consecuencias. Memoria del Simposio Internacional. Montevideo: UNESCO / UTA, pp. 55-74.

Mejías, E. (2010). Esclavos ¿libertos? v/s herederos, entre afectos, voluntades póstumas y el dominio. Chile. Siglo XVIII". En N. Siegrist \& H. Zapico (eds.); Familia, descendencia y patrimonio en España e Hispanoamérica. Siglos XVI-XIX. Buenos Aires: Universidad Nacional de Mar del Plata, pp. 129-154

Moritz Schwarcz, L. \& F. Dos Santos Gomes (2018). Dicionário da Escravidao e Liberdades. 50 textos críticos. San Pablo: Companhia Das Letras.

Navarrete, M. C. (2005). Génesis y desarrollo de la esclavitud en Colombia. Siglos XVI y XVII. Cali: Programa Editorial Universidad del Valle. 


\section{La libertad conquistada: Consideraciones sobre manumisión, gratitud y coerción en Charcas colonial (siglos XVI-XVIII)}

Ogass Bilbao, C. (2009). Por mi precio o mi buen comportamiento: oportunidades y estrategias de manumisión de los esclavos negros y mulatos en Santiago de Chile (1698-1750). Chungará (1) 42, pp. 141-184.

Ots Capdequí, J. M. (1945). Manual de Historia del Derecho español en las Indias y del derecho propiamente indiano. Buenos Aires: Losada.

Pérez Morales, E. (2017). Manumission on the Land: Slaves, Masters and Magistrates in Eighteenth-Century Monpox. Law and History Review, (5), 2, 2017.

Pita Pico, R. (2016). Amores prohibidos y anhelos de manumisión: las negras esclavas amantes de sus amos y su intrincada lucha por la libertad. Ciencias Sociales y Educación (5) 10, pp. 21-46.

Portilla, K. V. (2015). La coartación y el peculio, dos elementos claves en la manumisión de esclavos. Santiago de Cali (1750-1810). Fronteras de la Historia (20) 1, pp. 96-123.

Proctor, F. T. (2006). Gender and The manumission of Slaves in New Spain. Hispanic American Historical Review, (86) 2, pp. 309-336.

Recopilación de Leyes de Indias (1681). Madrid: Ivlian de Paredes, 4 ts.

Relaciones de los virreyes y Audiencias que han gobernado el Perú (1867). S. Lorente (ed.). Lima: Imprenta del Estado, t. I.

Revilla, P. (2020). Coerciones intrincadas. Trabajo africano e indígena en Charcas. Siglos XVI y XVII. Colección Scripta Autochtona (24). Cochabamba: ILAMIS, Itinerarios, adveniat, CIHA.

Revilla, P. (2019). Padre, no es nuestra voluntad seguir tolerando sus abusos: pronunciamiento afro-indígena para liberar al esclavo Clemente Chavarría (Charcas, siglo XVIII). Resistencia, delito y dominación en el mundo esclavo. Microhistorias de la esclavitud atlántica (siglos XVII-XIX). V. Paz Rozalén, M. Zeuske \& S. Luxán (eds.); Granada: Comares, pp. 129-144.

Revilla, P. (2018). No tengo derecho a dejarme anclar": Libertos en la representación social de su libertad (La Plata, Charcas 1540-1630). Historia y Cultura hoy. 13 entradas desde América Latina. M. E. Fernández \& V. Brangier (eds.); Rosario: Prohistoria, pp. 249-270.

Rosal, M. A. (2011). Manumisiones de esclavos en el Buenos Aires del temprano siglo XVII. Anuario de la Escuela de Historia Virtual (2) 2, pp. 6-19. 
Saignes, T. (2007). Historia del pueblo chiriguano. La Paz: Plural.

Secreto, M. V. \& Freire, J. (orgs.). Formas de libertade. Gratidão, condicionalidade e incertezas no mundo escravista nas Américas. Río de Janeiro: Mauad, pp. 129-155.

Sempat Assadourian, C. (1965). El tráfico de esclavos en Córdoba de Angola a Potosí (siglos XVI-XVII)". Cuadernos de Historia, 32, 60 pp.

San Martín Aedo, W. (2007). Petronila no vivía en la casa de los Miranda pero dentraba y salía en al casa y oyó decir que dicha Petronila era esclava. Esclavitud, libertades y resistencias. Hacia una propuesta integrativa a las condiciones de la negritud en Chile. Siglo XVII. Summa Historiae (2), 12, pp. 195-209.

Siete Partidas de Alfonso X El Sabio [1491 ([1256-1265)] (1988). Sevilla: Meinardo Ungut y Estanislao Polono, edición facsímil de 1491. Valladolid: Lex Nova.

Studer, E. (1958). La trata de negros en el Río de La Plata durante el siglo XVIII. Buenos Aires: Universidad de Buenos Aires / Instituto de Historia Argentina Doctor Emilio Ravignani.

Schwartz, S. B. (1974). The Manumission of Slaves in Colonial Brazil: Bahia, 16841745. The Hispanic American Historical Review (54), 4 pp. 603-635.

Scott, R. \& Hébrard J. M., Freedom Papers: An Atlantic Odyssey in the Age of Emancipation. Cambridge. Mass.: Harvard University Press.

Sweet, D. \& G. B. Nash (1987). Lucha por la supervivencia en la América colonial. México: Fondo de Cultura Económica.

Tandeter, E. [1976] 2015. Sobre el análisis de la dominación colonial. Boletín del Instituto de Historia Argentina y Americana "Dr. Emilio Ravignani", Tercera Serie (43): 17-30. Recuperado de http://ppct.caicyt.gov.ar/index.php/ravignani/article/view/8337

Vázquez de Espinosa, A. [1628-1629] 1948. Compendio y Descripción de las Indias Occidentales. Washington: The Smithsonian Institution.

Recibido: $26 / 04 / 2021$

Evaluado: $27 / 05 / 2021$

Versión Final: 16/07/2021 